\title{
Papillary hyperplasia of the gallbladder in pancreaticobiliary maljunction represents a senescence-related lesion induced by lysolecithin
}

\author{
Junpei Yamaguchi ${ }^{1}$, Motoko Sasaki ${ }^{1}$, Kenichi Harada ${ }^{1}$, Yoh Zen ${ }^{2}$, Yasunori Sato ${ }^{1}$, Hiroko Ikeda ${ }^{1}$, Keita Itatsu ${ }^{3}$, \\ Yukihiro Yokoyama ${ }^{3}$, Hisami Ando ${ }^{4}$, Tetsuo Ohta ${ }^{5}$, Akio Kubota ${ }^{6}$, Koichi Shimizu ${ }^{7}$, Yuji Nimura ${ }^{8}$, Masato Nagino ${ }^{3}$ \\ and Yasuni Nakanuma'
}

Cellular senescence, an irreversible growth arrest, is considered to play as safeguard against malignant progression, though such a mechanism is speculative in human carcinogenesis. In gallbladder carcinoma, cholecystolithiasis and pancreaticobiliary maljunction (PBM) are major risk factors. Here, by using 113 surgically resected gallbladders and cultures of human gallbladder epithelial cells (HGECs) and gallbladder carcinoma cell line (TGBC2TKB), we examined carcinogenesis with respect to cellular senescence. Among 15 cases of PBM in which carcinoma was found in 4 cases, nonneoplastic gallbladder mucosa showed diffuse papillary hyperplasia (PHP). PHP was not found in gallbladders with cholecystolithiasis. Interestingly, PHP exhibited senescent features such as expression of p16 $6^{\text {INK4A }}$ and low cell proliferative activity. In contrast, EZH2, a polycomb group protein, was overexpressed in intraepithelial neoplasm and carcinoma in gallbladders with cholecystolithiasis. In PBM, EZH2 was expressed only in carcinoma foci but not in PHP. Cultured HGECs treated with lysolecithin, the level of which is elevated in gallbladder bile of PBM, showed increased expression of $\mathrm{p} 16^{\mathrm{INK} 4 \mathrm{~A}}$ and senescence-associated $\beta$-galactosidase. Conversely, enforced overexpression of EZH2 in senescent HGECs reduced p16 ${ }^{\text {INK4A }}$ expression. A knockdown of EZH2 in cultured TGBC2TKB cells increased p16 ${ }^{\text {INK4a }}$ expression. In conclusion, PHP in PBM may act as a barrier to malignant transformation for decades. EZH2 may be responsible for the escape from cellular senescence followed by malignant transformation in the gallbladder of PBM. Laboratory Investigation (2009) 89, 1018-1031; doi:10.1038/labinvest.2009.65; published online 29 June 2009

KEYWORDS: cellular senescence; cholecystolithiasis; gallbladder carcinoma; pancreaticobiliary maljunction; papillary hyperplasia

Gallbladder carcinoma is an aggressive and dismal disease, affecting mainly older people and women. ${ }^{1,2}$ Among risk factors for the development of gallbladder carcinoma, cholecystolithiasis is the most important. ${ }^{1-3}$ Porcelain gallbladder, gallbladder adenoma and adenomyomatosis, and pancreaticobiliary maljunction ( $\mathrm{PBM})$ are also known as risk factors, and the carcinogenesis and precancerous lesions may be different in the gallbladder depending on the risk factors. ${ }^{1-3}$

PBM is defined as the union of the pancreatic and common bile ducts outside the wall of the duodenum, beyond the influence of the sphincter of Oddi. ${ }^{3-7}$ Normally, the pancreaticobiliary duct and junction are governed by sphincter, but as a result of the anomaly, pancreatic juice can reflex into the common bile duct. PBM patients are known to be associated with bile duct dilatation and also biliary tract carcinoma, especially in the Far East. ${ }^{3-7}$ Patients who develop gallbladder carcinoma in association with $\mathrm{PBM}$ are usually 10 years younger than those without PBM. Synchronous primary cancers of the gallbladder and common bile duct have also been associated with PBM. Although PBM is reportedly rare in the West, ${ }^{8}$ the impact of this disease in the biliary tract carcinogenesis deserves much attention of Western researchers and clinicians.

\footnotetext{
'Department of Human Pathology, Kanazawa University Graduate School of Medicine, Kanazawa, Japan; ${ }^{2}$ Department of Diagnostic Pathology, Kanazawa University Hospital, Kanazawa, Japan; ${ }^{3}$ Department of Surgical Oncology, Nagoya University Graduate School of Medicine, Nagoya, Japan; ${ }^{4}$ Department of Pediatric Surgery, Nagoya University Graduate School of Medicine, Nagoya, Japan; ${ }^{5}$ Department of Gastroenterologic Surgery, Kanazawa University Graduate School of Medicine, Kanazawa, Japan; ${ }^{6}$ Department of Pediatric Surgery, Osaka Medical Center and Research Institute for Maternal and Child Health, Osaka, Japan; ${ }^{7}$ Department of Surgery, Toyama Prefectural Central Hospital, Toyama, Japan and ${ }^{8}$ Department of Gastroenterological Surgery, Aichi Cancer Center Hospital, Aichi, Japan Correspondence: Dr Y Nakanuma, MD, Department of Human Pathology, Kanazawa University Graduate School of Medicine, Kanazawa 920-8640, Japan. E-mail: pbcpsc@kenroku.kanazawa-u.ac.jp 
In the patients with PBM, the gallbladder shows frequently papillary hyperplasia (PHP) of the mucosa and PHP has been considered an important precursor lesion for gallbladder carcinoma. ${ }^{3-5}$ It has been postulated in PBM that the reflex of pancreatic juice into the common bile duct and the stagnation of pancreatic juice mixed with bile have been considered to play an important role in the pathophysiology of PBM, including biliary tract carcinoma. ${ }^{3-10} \mathrm{~A}$ high concentration of lysolecithin (LL) was reported in the gallbladder bile of $\mathrm{PBM},{ }^{3-7}$ and LL is produced from lecithin by activated phospholipase A2 in the refluxing pancreatic juice in PBM. LL and other altered bile components may be responsible for the development of PHP and also carcinoma of the gallbladder in PBM. ${ }^{3-7}$

Although gallstones seem to be closely associated with gallbladder carcinoma, there is no evidence of direct causal relationship between them. Lining epithelia of the biliary tract including the gallbladder are known to show intraepithelial atypical/proliferative lesions closely associated with the development of carcinoma. ${ }^{1,11,12}$ In the large bile ducts of hepatolithiasis, these lesions are named as biliary intraepithelial neoplasia (BilIN) and they are subdivided into BilIN-1(low-grade dysplasia), BilIN-2 (high-grade dysplasia), and BilIN-3 (carcinoma in situ). ${ }^{11,12}$ Recently, we reported that these lesions show serial molecular changes along their progression. That is, the expression of $\mathrm{p} 16^{\mathrm{INK} 4 \mathrm{~A}}$, a major tumor suppressor, was frequent in BillN-1, but was decreased in BilIN-2/3 and invasive carcinoma. Instead, EZH2, a polycomb group transcriptional repressor, showed a stepwise increase from BilIN-1, -2, and -3 to invasive carcinoma, suggesting that overexpression of EZH2 followed by decreased expression of $\mathrm{p} 16^{\mathrm{INK} 4 \mathrm{a}}$ is involved in the multistep carcinogenesis through BiliNs of the large bile ducts of hepatolithiasis. ${ }^{12}$ Amplification of EZH2 is reported in various cancers, ${ }^{12,13}$ and upregulation of EZH2 is reported to indicate an increased risk of neoplastic transformation. ${ }^{14}$ In cholelcystolithiasis, however, the role of EZH2 and $\mathrm{p} 16^{\mathrm{INK} 4 \mathrm{a}}$ in the precursor lesions and carcinoma remains speculative.

Cellular senescence was first described as permanent growth arrest due to telomere attrition, and oxidative stress and DNA damage can also trigger senescence prematurely. ${ }^{13-15}$ Senescence, particularly the telomere-independent form, is reported to act as a safeguard mechanism against malignant transformation. ${ }^{16}$ For example, nevi composed of melanocytes showing cellular senescence may reside without malignant transformation for years. ${ }^{17}$ As for the emergence of overt malignant tumors from the senescent state, acquisition of an escape mutation or expansion from a clone bypassing senescence is speculated. In patients with PBM, the gallbladder mucosa is known to continuously shows PHP from infants through to adults, ${ }^{18}$ whereas the gallbladder carcinoma in PBM patients just increases with age with a peak at 50 years, ${ }^{4-6}$ implying that the gallbladder mucosa showing PHP does not undergo malignant for decades, raising a possibility that PHP represents a senescent-related lesion against malignant transformation.

EZH2 is suggested to be involved in the regulation of p16 ${ }^{\mathrm{INK} 4 \mathrm{a}}$, an important factor in the process of senescence, and importantly, these two molecules seem to be involved in the biliary tract carcinogenesis. ${ }^{12}$ There have been no studies on PHP with respect to cellular senescence and activation of EZH2. Furthermore, it remains only speculative what mechanism(s) prevent malignant transformation in the gallbladder for decades in patients with PBM, and what mechanisms initiate the gallbladder carcinoma in adult PBM patients.

In this study using gallbladders and cultures of gallbladder epithelial cells and gallbladder carcinoma cell line, we tried to evaluate carcinogenetic pathways in the presence of cholecystolithiasis and PBM. We also tried to examine the significance of PHP in the carcinogenesis in PBM with respect to EZH2 and cellular senescence.

\section{MATERIALS AND METHODS \\ Cellular Senescent Markers}

In this study, $\mathrm{p} 16^{\mathrm{INK} 4 \mathrm{~A}}$, SA- $\beta$-Gal, and $\gamma \mathrm{H} 2 \mathrm{AX}$ were used as a cellular senescence marker: $\mathrm{p} 16^{\mathrm{INK} 4 \mathrm{~A}}$ is often highly expressed in senescent cells in vitro. A relationship between senescenceassociated $\beta$-galactosidase (SA- $\beta$-Gal) activity and senescent cells is generally accepted, especially in cultured cells. ${ }^{19}$ Recent studies suggest that DNA damage and DNA damage signaling are causative of different forms of senescence, including not only telomere dysfunction, but also oncogeneinduced senescence, ${ }^{20}$ and $\mathrm{H} 2 \mathrm{AX}$, a variant of the nucleosome core histone H2A, undergoes phosphorylation at Ser 139 in response to DNA damage, and this phosphorylated H2AX has been named $\gamma \mathrm{H} 2 \mathrm{AX}{ }^{21}$

\section{Human Tissue Studies \\ Classification of hyperplastic and neoplastic lesions of gallbladder}

We divided intraepithelial neoplasia of the lining epithelia of gallbladder into BilIN-1 (low-grade dysplasia), BillN-2 (high-grade dysplasia), and BilIN-3 (carcinoma in situ). ${ }^{11,12}$ The former two were collectively termed BilIN-1/2 (Figure 1a and $\mathrm{b}$ ), and BilIN-3 was included in gallbladder carcinoma (CarGB). CarGB was divided histologically into well, moderately, and poorly differentiated adenocarcinoma, and papillary carcinoma. PHP is characterized by diffuse papillary infolding of the lining tall epithelium of the gallbladder. There is no evident cytological or nuclear atypia.

\section{Preparation of tissue specimens}

The gallbladders from 15 patients with PBM, in which 4 cases were associated with carcinoma (BilIN-3 and invasive carcinoma), were used. Gallstones were not found in these cases. A total of 87 gallbladders with cholecystolithiasis were used: 10 with no BilIN lesions (CholGB), 39 with several foci of BillN-1/2 lesions, and 38 with BillN-3 and invasive 

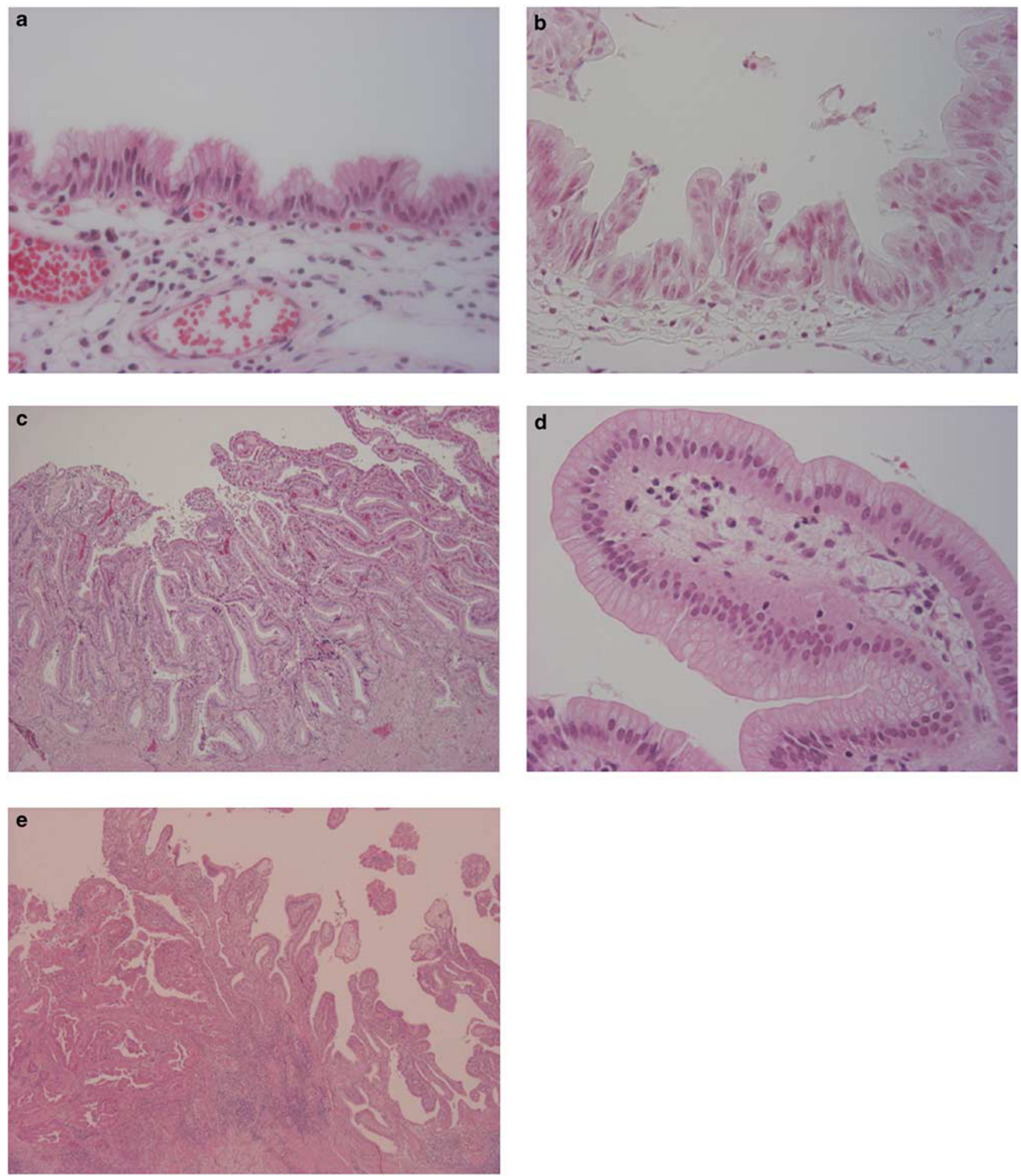

Figure 1 Histology of precursor lesions of the gallbladder. Biliary intraepithelial neoplasm (BillN)-1 (a) and BillN-2 (b) showed loss of nuclear polarity and mild or moderate cellular atypia. Papillary hyperplasia was seen in the gallbladder of pancreaticobiliary maljunction (c: low-power field; $\mathbf{d}$ : high-power field). (e) Histology of papillary hyperplasia (PHP) (right) and carcinoma (left) in pancreaticobiliary maljunction. Carcinoma was found in background of PHP. Original magnification: $\times 400(\mathbf{a}, \mathbf{b}$ and d), $\times 100(\mathbf{c})$, and $\times 40(\mathbf{e})$.

carcinoma (CarGB; Table 1). In these cases, chronic cholecystitis was found in the nonneoplastic mucosa. CarGB cases including BIlIN-3 comprised of 11 well, 12 moderately, and 9 poorly differentiated adenocarcinomas, and 6 papillary adenocarcinomas. As normal controls, surgically resected gallbladders from 11 patients who underwent gastrectomy for 
Table 1 Main clinicopathological features of cases examined in this study

\begin{tabular}{lccc}
\hline Gallbladder & Cases $(n)$ & $\begin{array}{c}\text { Age (years); } \\
\text { mean } \pm \text { s.d. } \\
\text { (range) }\end{array}$ & $\begin{array}{c}\text { Gender } \\
\text { (male/ } \\
\text { female) }\end{array}$ \\
\hline Normal gallbladder (NorGB) & 11 & $73.5 \pm 6.5(85-61)$ & $7: 4$ \\
& 15 & $46.4 \pm 18.8(18-77)$ & $5: 10$ \\
PBM & 11 & $41.5 \pm 17.9(18-64)$ & $4: 7$ \\
$\quad$ Without carcinoma & 4 & $60.0 \pm 15.9(39-77)$ & $1: 3$ \\
$\quad$ With carcinoma & 10 & $61.0 \pm 14.6(38-81)$ & $7: 3$ \\
Cholecystolithiasis without & & & $21: 18$ \\
BillN or carcinoma (CholGB) & 39 & $66.9 \pm 18.0(23-91)$ & $16: 22$ \\
Cholecystolithiasis with BillN-1/2 & 38 & $77.1 \pm 8.3(57-90)$ & \\
Cholecystolithiasis with carcinoma & 38 & & \\
including BillN-3 (CarGB) & & & \\
\hline
\end{tabular}

BillN, biliary intraepithelial neoplasia; PBM, pancreaticobiliary maljunction.

gastric cancer and cholecystectomy, a part of a regular operation, were used (NorGB).

All these surgically resected gallbladders were fixed in $10 \%$ formalin. After embedding in paraffin, about 20 serial thin sections were cut from each block, and used for histological and immunohistochemical analyses. This study was approved by the Committee of Ethics in Kanazawa University.

\section{Immunohistochemistry}

The expressions of p16 ${ }^{\mathrm{INK} 4 \mathrm{~A}}$, EZH2, $\gamma \mathrm{H} 2 \mathrm{AX}$, and Ki-67 were assessed immunohistochemically in nonneoplastic and neoplastic gallbladders, using monoclonal antibodies: antip16 ${ }^{\mathrm{INK} 4 \mathrm{~A}}$ (clone JC2; Neomarkers, CA, USA), anti-EZH2 (clone 11; Transduction, San Jose, CA, USA), anti- $\gamma \mathrm{H} 2 \mathrm{AX}$ (clone JBW301; Upstate Biotech, Lake Placid, NY, USA), and anti-Ki67 (clone MIB-1; DAKO, Glostrup, Denmark), respectively. That is, deparaffinized sections were pretreated in EDTA buffer, $\mathrm{pH} 9$ at $121^{\circ} \mathrm{C}$ for EZH2, or in citrate buffer, $\mathrm{pH} 6$ at $121^{\circ} \mathrm{C}$ for $\mathrm{p} 16^{\mathrm{INK} 4 \mathrm{~A}}$ or in a microwave in citrate buffer $\left(\mathrm{pH} \mathrm{6)}\right.$ at $95^{\circ} \mathrm{C}$, for $\mathrm{Ki}-67$ and $\gamma \mathrm{H} 2 \mathrm{AX}$. After the pretreatment with $1 \% \mathrm{H}_{2} \mathrm{O}_{2}$ in methanol to block endogenous peroxidase activity and then with Protein Block Serum to block nonspecific reactions, the sections were incubated overnight at $4{ }^{\circ} \mathrm{C}$ with each primary monoclonal antibody at the optimized dilutions. Thereafter, the sections were incubated with the secondary antibodies conjugated to a peroxidase-labeled polymer, the EnVision + system (DAKO), or Histofine Simple Stain MAX PO (G) (Nichirei, Tokyo, Japan). A diaminobenzidine tetrahydrochloride solution containing hydrogen peroxide was used as the chromogen. For a negative control, a similar dilution of the control mouse IgG (DAKO) was applied.

Percentage of cells positive for $\mathrm{p} 16^{\mathrm{INK} 4 \mathrm{~A}}, \mathrm{EZH} 2, \gamma \mathrm{H} 2 \mathrm{AX}$, and Ki-67, was semiquantitatively calculated in high-power fields of two or three foci containing about 100 contiguous epithelial cells, and the mean was regarded as the labeling index (LI) of individual proteins in each case. LIs of p16 ${ }^{\mathrm{INK} 4 \mathrm{~A}}$, EZH2, and $\gamma \mathrm{H} 2 \mathrm{AX}$ were compared among normal, hyperplastic, preneoplastic, and neoplastic lesions. Proliferative activities of these cells were assessed using Ki-67 LI.

\section{Cell Culture Study}

Primary culture of human gallbladder epithelial cells

Human gallbladder epithelial cells (HGECs) were established from a surgically resected gallbladder with cholecystolithiasis as described, ${ }^{22}$ and grown as monolayers. Epithelial nature of these cells was confirmed by the expression of CK7. HGECs were incubated in a culture medium as described, and HGECs between passages 4 and 8 were used.

\section{Culture of carcinoma cell line}

The human gallbladder carcinoma cell line, TGBC2TKB (RCB1130), was provided by the Riken Cell Bank (Tsukuba, Japan). TGBC2TKB cells were maintained in DMEM containing 5\% fetal bovine serum and antibiotic-antimyotic (Gibco, Rockville, MD, USA).

\section{Preparation of model bile solutions}

Model bile solution containing lysolecithin (MB-LL) and containing lecithin (control MB) were prepared for cell culture study. Cholesterol, Egg lecithin, egg lysolecithin, and sodium taurocholate were obtained from Sigma (St Louis, MO, USA) and stored at $-80^{\circ} \mathrm{C}$. The procedures for model bile preparation were slight modifications of those described previously. ${ }^{23}$ In brief, stock model bile solutions were prepared as follows. Aliquots of taurocholate in methanol, either of lecithin or lysolecithin in chloroform/methanol, and cholesterol in methanol were added to a vial equipped with a Teflon cap to yield the desired amount of these three lipids. All model bile solutions used in this study contained $9.6 \mathrm{~mol}$ $\%$ cholesterol, $8 \mathrm{~g}$ of total lipids per $100 \mathrm{ml}$, and a bile salt/ lecithin molar ratio of 2.3:1. After the mixture was flushed with nitrogen, it was shaken at $37^{\circ} \mathrm{C}$ overnight, and the organic solvent was then evaporated under a stream of nitrogen until the mixture had condensed to a viscous paste. To complete solvent removal, the mixture was lyophilized. Lastly, the required volume of Hanks' balanced salt solution was added to preheated lyophilized lipids. The $\mathrm{pH}$ of each solution was adjusted to 7.5 and the mixture was flushed with nitrogen. The resultant suspension was shaken at a constant speed of 100 r.p.m. in environmental incubator shaker at $55^{\circ} \mathrm{C}$ until microscopically isotropic (at least $24 \mathrm{~h}$ ).

\section{Assay for Cellular Senescence and Cell Proliferative Activity Cellular senescence}

SA- $\beta$-Gal activity was detected using a senescence detection kit (BioVision, Mountain View, CA, USA). The proportion of 
senescent cells was assessed by counting the percentage of SA$\beta$-Gal-positive cells among at least $1 \times 10^{3}$ cells.

\section{Cell proliferative activities}

Cell proliferative activity was assessed using 5-bromo-2'deoxyuridine (BrdU) Labeling and Detection Kit I (Roche, Nonnenwald, Germany). The nuclei were simultaneously stained with 4',6-diamidino-2-phenylindole. At least $1 \times 10^{3}$ cells were checked and counted to determine the BrdU-LI using a fluorescence microscope. Serial proliferation of the cells was assessed using Cell Proliferation Reagent WST-1 (Roche).

\section{Western Blotting}

Proteins were extracted from cultured cells using T-PER tissue protein extraction reagent (Pierce Chemical Co., Rockford, IL, USA), and the total amount of protein was measured spectrometrically. The $25 \mathrm{mg}$ of the protein was subjected to $10 \%$ SDS-polyacrylamide electrophoresis and electrophoretically transferred onto a nitrocellulose membrane. The membrane was incubated with primary antibodies against anti-p16 ${ }^{\mathrm{INK} 4 \mathrm{~A}}$ (1:100; clone JC8; Santa Cruz), EZH2 (1:500), $\gamma \mathrm{H} 2 \mathrm{AX}$ (1:1000), and $\beta$-actin (1:5000; Abcam, Cambridge, UK). The protein expression was detected using a chemiluminescence kit (Thermo Scientific, Waltham, MA, USA).

\section{RT-PCR}

Total RNA $(1 \mu \mathrm{g})$ was extracted from cultured cells using an RNA extraction kit (RNeasy Mini; Qiagen, Tokyo, Japan) and used to synthesize cDNA with reverse transcriptase (ReverTra Ace; Toyobo Co., Osaka, Japan). PCR amplification was performed in a total volume of $25 \mu \mathrm{l}$ containing $1 \mu \mathrm{l}$ of cDNA, $0.2 \mathrm{mmol} / \mathrm{l} \mathrm{dNTPs}, 1 \mu \mathrm{mol} / \mathrm{l}$ each of $5^{\prime}$ - and $3^{\prime}$ - primers, and $2.5 \mathrm{U}$ of TaqDNA polymerase (Takara EX Taq; Takara Bio) with an annealing temperature of $58^{\circ} \mathrm{C}$ for p16, $54^{\circ} \mathrm{C}$ for $\mathrm{EZH} 2$, and $56^{\circ} \mathrm{C}$ for G3PDH. The sequences of the primers were as follows: EZH2, $5^{\prime}$-GTGGAGAGATTATTT CTCAAGATG-3' (forward) and 5'-CCGACATACTTCAGGG CATCAGCC-3' (reverse); p16, 5'-CCCGCTTTCGTAGTTTT CAT-3' (forward) and $5^{\prime}$-TTATTTGAGCTTTGGTTCTG-3' (reverse); and G3PDH, 5'-GAACGGGAAGCTCACTGGCAT GGC-3' (forward) and 5'-TGAGGTCCACCACCCTGTTGC Tg- $3^{\prime}$ (reverse). The number of PCR cycles was 27. For each reaction, an initial denaturation cycle of $94^{\circ} \mathrm{C}$ and a final cycle of $72^{\circ} \mathrm{C}$ were incorporated. The PCR products were subjected to $2 \%$ agarose gel electrophoresis and stained with ethidium bromide. A semiquantitative analysis of the gel image was performed using public domain NIH image software and the difference compared with G3PDH expression was calculated.

\section{Knockdown of EZH2 by Small Interfering RNA}

Validated small interfering RNA (siRNA) for EZH2 and negative control siRNA were purchased from Santa Cruz
Biotech (Santa Cruz, CA, USA) and Qiagen (Hilden, Germany), respectively. One day before transfection, cells were plated in 12-well plates $\left(3-5 \times 10^{4}\right.$ cells) or Lab-Tek chambers $\left(1 \times 10^{4}\right.$ cells), and then transiently transfected with either EZH2 or control siRNA ( $150 \mathrm{nM})$, using Lipofectamine 2000 (Invitrogen, Carlsbad, CA), according to the manufacturer's protocol.

\section{Transfection of EZH2-Overexpression Vector}

The EZH2-overexpression plasmid and control vector were transfected into HGECs using Lipofectamine 2000 (Invitrogen) according to the manufacture's protocol. The EZH2 plasmid was a kind gift from Dr. T Jenuwein (Research Institute of Moleclar Pathology, Vienna). ${ }^{24}$

\section{Immunofluorescence Staining of the Cultured Cells}

Cultured cells (HGECs and TGBC2TKB) grown in a Lab-Tek chamber were fixed and stained using the primary antibodies for $\gamma \mathrm{H} 2 \mathrm{AX}$ or $\mathrm{p} 16^{\mathrm{INK} 4 \mathrm{~A}}$ described above. After incubation with the primary antibodies overnight, and then Alexa-Flour 488- or 568-labelled anti-mouse IgG, the sections were observed under a fluorescence microscope.

\section{Statistical Analysis}

Data are expressed as the mean \pm s.d. For comparisons of multiple groups, we used Welch's $t$-test. Differences with values of $P<0.05$ were considered significant.

\section{RESULTS}

\section{Human Tissue Studies}

In all 15 cases of PBM, the nonneoplastic mucosa showed PHP (Figure 1c and d), but not BilIN-1/2. In four cases of PBM associated with CarGB, carcinoma was found in the background of PHP (Figure 1e). In contrast, PHP was not found in gallbladder mucosa with cholecystolithiasis.

\section{Expression of p $16^{I N K 4 A}$ and EZH2}

EZH2 was expressed in the nuclei of gallbladder epithelial cells including carcinoma cells, whereas $\mathrm{p} 16^{\mathrm{INK} 4 \mathrm{~A}}$ was found in the nuclei and/or cytoplasm of these cells (Figure 2). EZH2 was clearly and frequently expressed in CarGB (LI, $56.2 \pm 21.0 \%$ ), whereas it was faint and infrequent in NorGB and CholGB ( $3.1 \pm 5.2 \%$ and $9.5 \pm 10.4 \%$; Figure $3 a)$. EZH2 was strongly and frequently expressed in BillN-1/2 in cholecystolithiasis, whereas its expression was faint and infrequent in PHP in PBM (Figure $2 \mathrm{~b}$ and c), and its LI was higher in the former $(55.3 \pm 27.1 \%)$ than in the latter $(20.3 \pm 21.9 \% ; P<0.05$; Figure $3 a)$.

p16 ${ }^{\mathrm{INK} 4 \mathrm{~A}}$ was expressed variably in CarGB $(16.4 \pm 28.5 \%)$, whereas its expression was negligible in NorGB and CholGB $(0.3 \pm 0.9 \%$ and $0.6 \pm 1.9 \%)$. p $16^{\mathrm{INK} 4 \mathrm{~A}}$ was evidently and frequently expressed in PHP in comparison with BillN-1/2 (Figure $2 \mathrm{~b}$ and $\mathrm{c}$ ), and its LI was higher in PHP $(45.0 \pm 22.7 \%)$ than in BilIN-1/2 $(9.8 \pm 15.5 \% ; P<0.05$; Figure 3a). When LI of EZH2 and that of p16 $6^{\mathrm{INK} 4 \mathrm{~A}}$ in BilIN1/ 

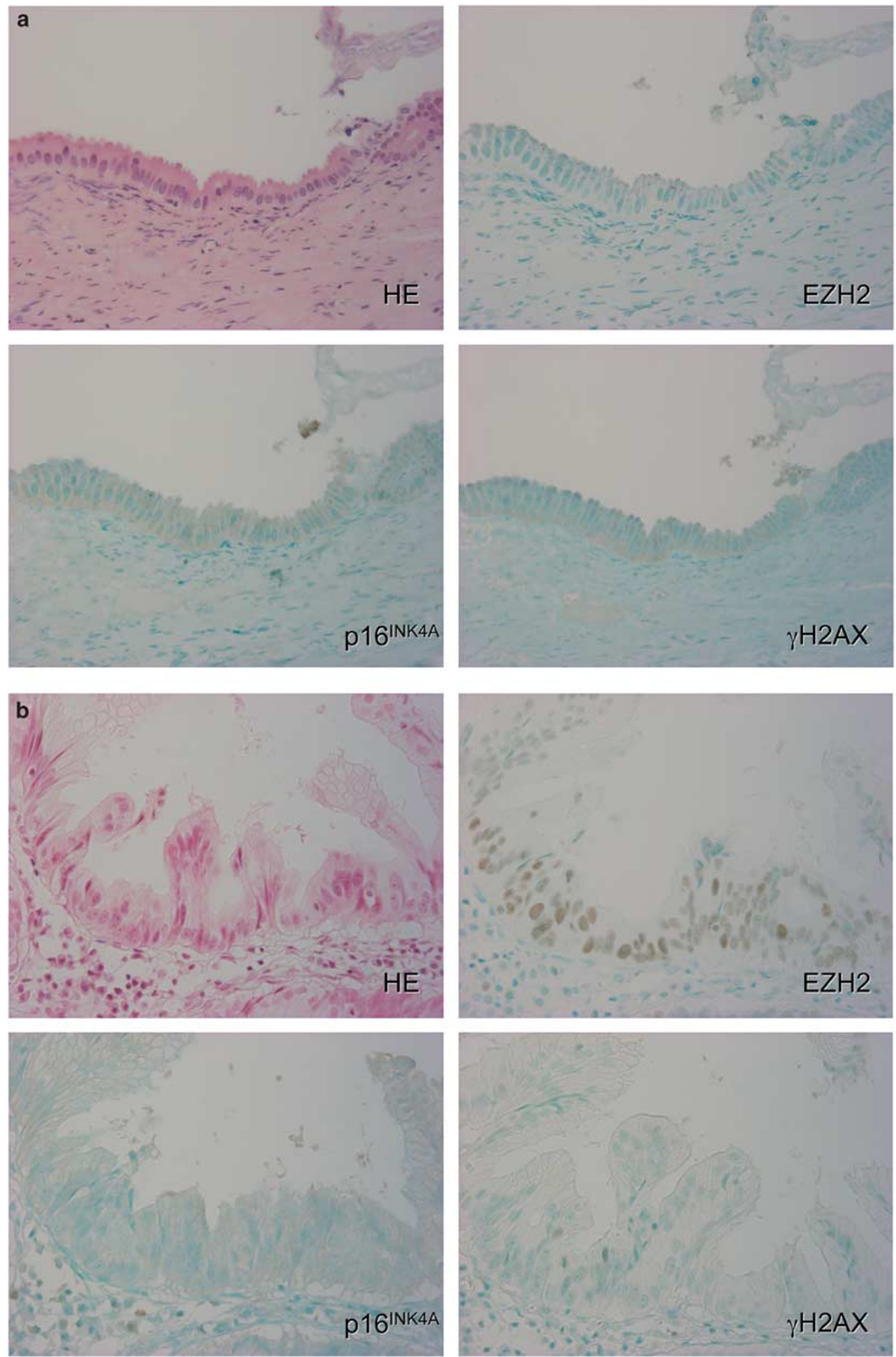

Figure $2 \mathrm{HE}$ and immunohistochemical expression of $\mathrm{p} 16^{\mathrm{INK} 4 \mathrm{~A}}, \mathrm{EZH} 2$, and $\gamma \mathrm{H} 2 \mathrm{AX}$ in normal gallbladder (a), biliary intraepithelial neoplasm (BillN)-1/2 (b), papillary hyperplasia (PHP) in pancreaticobiliary maljunction (PBM) (c), and cancerous lesions in PBM (the same case as in c) (d). p16 $6^{\text {INK4A }}$ is frequently expressed in PHP in PBM (arrows), but its staining was heterogeneous. On the other hand, $\gamma \mathrm{H} 2 \mathrm{AX}$ expression was homogenous in the same lesion. EZH 2 is frequently expressed in cancer and BillN-1/2. 

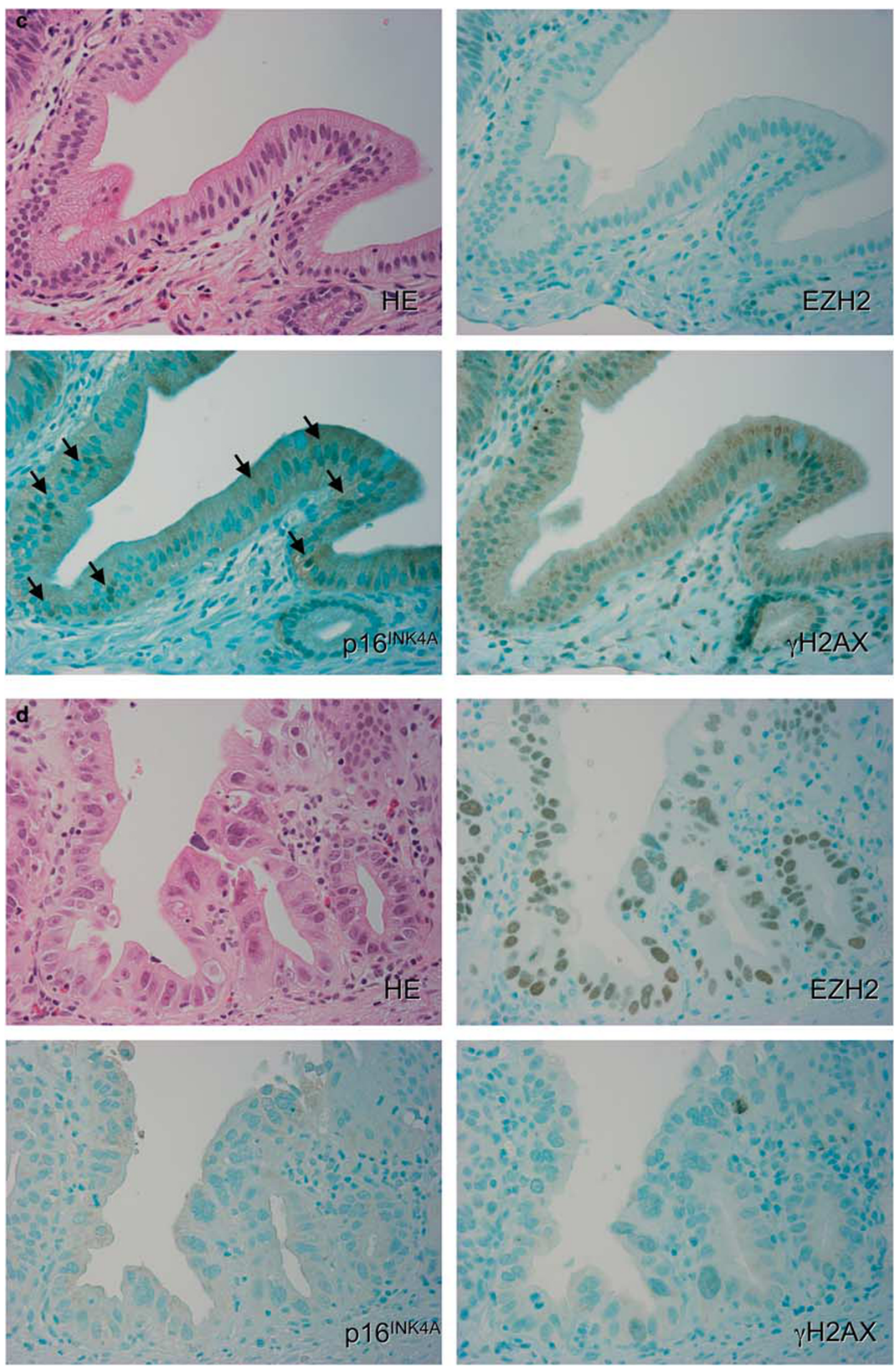

Figure 2 Continued. 
a
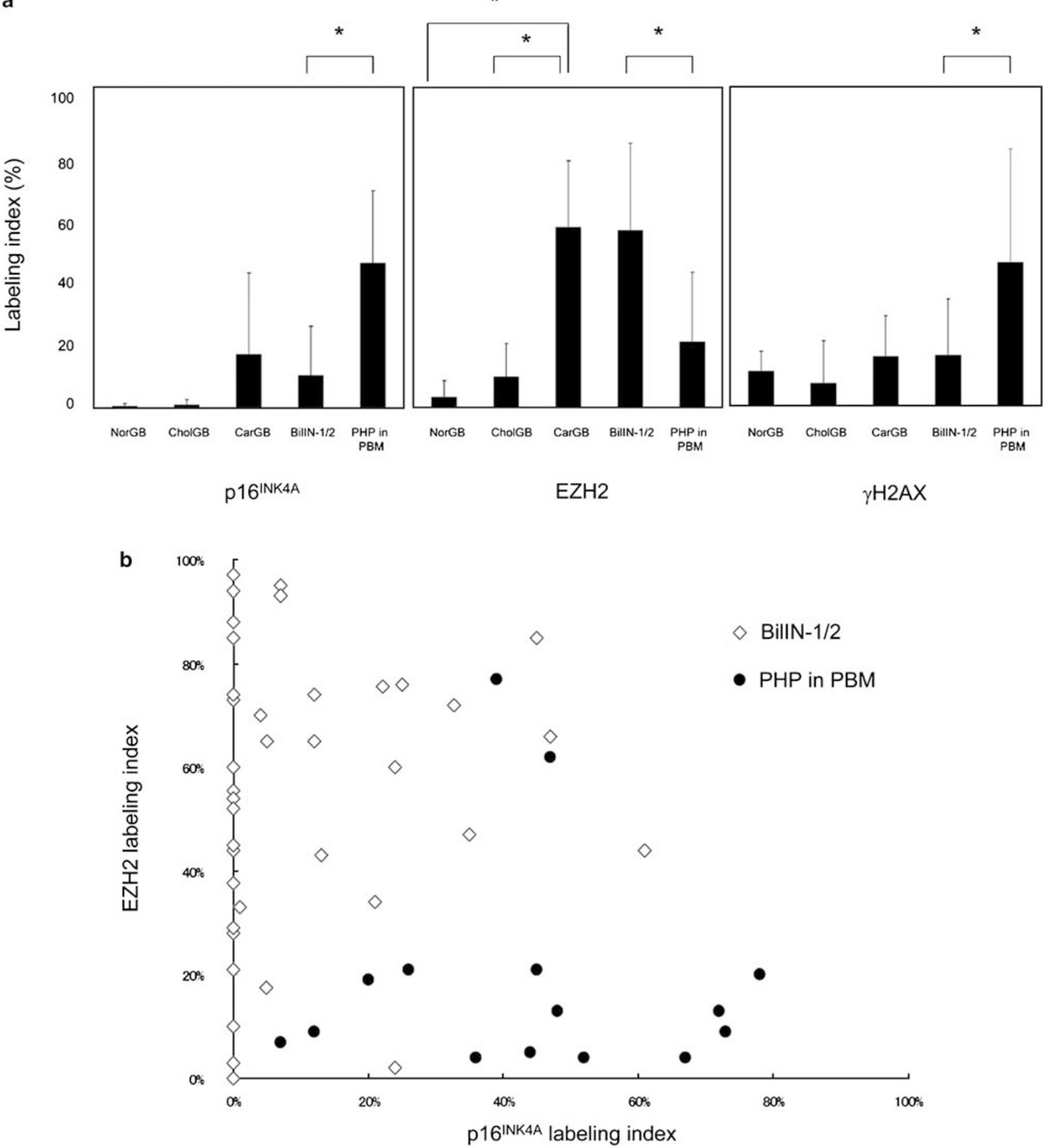

Figure 3 (a) Semiquantitative evaluation of the expression of $\mathrm{p} 16^{\mathrm{INK} 4 \mathrm{~A}}, \mathrm{EZH} 2$, and $\gamma \mathrm{H} 2 \mathrm{AX}$ in normal gallbladder (NorGB), chronic cholecystitis without biliary intraepithelial neoplasm (CholGB), gallbladder carcinoma (CarGB), biliary intraepithelial neoplasm (BillN)-1/2, and papillary hyperplasia (PHP) in pancreaticobiliary maljunction (PBM). The labeling index (LI) reflects the percentage of cells immunohistochemically positive for individual proteins in each lesion. ${ }^{\star} P<0.01$. (b) Distribution of the expression of $\mathrm{p} 16^{\mathrm{INK} 4 \mathrm{~A}}$ and that of EZH2 of biliary intraepithelial neoplasm (BillN)-1/2 in cholecystolithiasis and papillary hyperplasia (PHP) in pancreaticobiliary maljunction (PBM) shown by percentages. Expression of p16 ${ }^{\mathrm{INK} 4 \mathrm{~A}}$ and that of EZH2 are inversely correlated $(P<0.05, r=-0.326)$.

2 and PHP cases were plotted together, the expression of $\mathrm{p} 16^{\mathrm{INK} 4 \mathrm{~A}}$ and $\mathrm{EZH} 2$ was found to be inversely correlated; most of the BilIN-1/2 cases were categorized into the EZH2-positive/p16 ${ }^{\mathrm{INK} 4 \mathrm{~A}}$-negative group and most of the $\mathrm{PHP}$ cases into the EZH2-negative/p16 ${ }^{\mathrm{INK} 4 \mathrm{~A}}$-positive group (Figure 3b). 


\section{Cell proliferative activities}

Ki-67 LI was higher in BillN-1/2 (26.8 $\pm 26.5 \%)$ than PHP $(6.7 \pm 11.6 \%)(P<0.05)$. Ki-67 LI of CarGB including BilIN3 was $35.1 \pm 21.7 \%$. That of NorGB and CholGB was $0.4 \pm 0.7 \%$ and $1.1 \pm 0.9 \%$, indicating that epithelial cells of BilIN1/2 were more proliferative like BilIN3 and invasive CarGB, whereas the proliferative activity of PHP was similar to NorGB level.

\section{Expression of $\gamma \mathrm{H} 2 \mathrm{AX}$}

$\gamma \mathrm{H} 2 \mathrm{AX}$, a marker of DNA damage, was expressed in the nuclei of the epithelial cells in the form of multiple foci in nonneoplastic and neoplastic gallbladder epithelium. In contrast to $\mathrm{p} 16^{\mathrm{INK} 4 \mathrm{~A}}$, which had a scattered distribution, $\gamma \mathrm{H} 2 \mathrm{AX}$ was homogeneously expressed in PHP (Figure 2c). The expression of $\gamma \mathrm{H} 2 \mathrm{AX}$ was more frequent in PHP in PBM cases than in BilIN1/2 in cholecystolithiasis, and its LI was higher in PHP $(44.6 \pm 35.9 \%)$ than in BilIN1/2 $(15.6 \pm 17.8 \% ; P<0.05)$. Its expression in CarGB (LI, $15.2 \pm 12.9 \%$ ) was comparable to BilIN1/2. Its LI in NorGB $(10.5 \pm 6.3 \%)$ and CholGB $(6.9 \pm 13.4 \%)$ were low in comparison with that in PHP (Figure 3a).

\section{BillN-3 and invasive carcinoma in gallbladders with PBM and} those with cholecystolithiasis

The above-mentioned immunohistochemical features of BiIIN-3 and invasive carcinoma were similar between these two groups.

\section{Cell Culture Studies}

Treatment of cultured HGECs by lysolecithin

Induction of Growth Arrest in Cultured HGECs. Under the hypothesis that senescence occurs in the gallbladder of PBM and that a high concentration of LL in bile relates to such changes, we treated cultured HGECs with $100 \mu \mathrm{M} \mathrm{LL}$, MB-LL (containing $100 \mu \mathrm{M} \mathrm{LL}$ ) and control MB. As shown in Figure 4a, the proliferation of HGECs was markedly inhibited by the treatment with LL and to a lesser degree, by the treatment with MB-LL, with a plateau in the growth curve reached by day 4 . As shown in Figure $4 \mathrm{~b}$, the proliferation of HGECs was inhibited by the treatment with control model bile with LL $(50 \mu \mathrm{M})$, with a plateau in the growth curve reached by day 4 . The growth rate was slightly high by day 4 in HGECs with this treatment. Relative cell numbers were markedly decreased by the treatment with control model bile with higher concentration of LL (100 and $150 \mu \mathrm{M})$, indicating cell death by these treatments. In vitro BrdU assay performed 4 days after the treatment with LL $(100 \mu \mathrm{M})$ and MBLL (containing $100 \mu \mathrm{M} \mathrm{LL}$ ) showed that cell proliferative activity was significantly low in comparison to the solvent control and control MB (Figure 4c).

Expression of Senescence Markers. We examined the expression of several markers of senescence in the growth-arrested HGECs induced by LL. The number of SA- $\beta$-Gal-
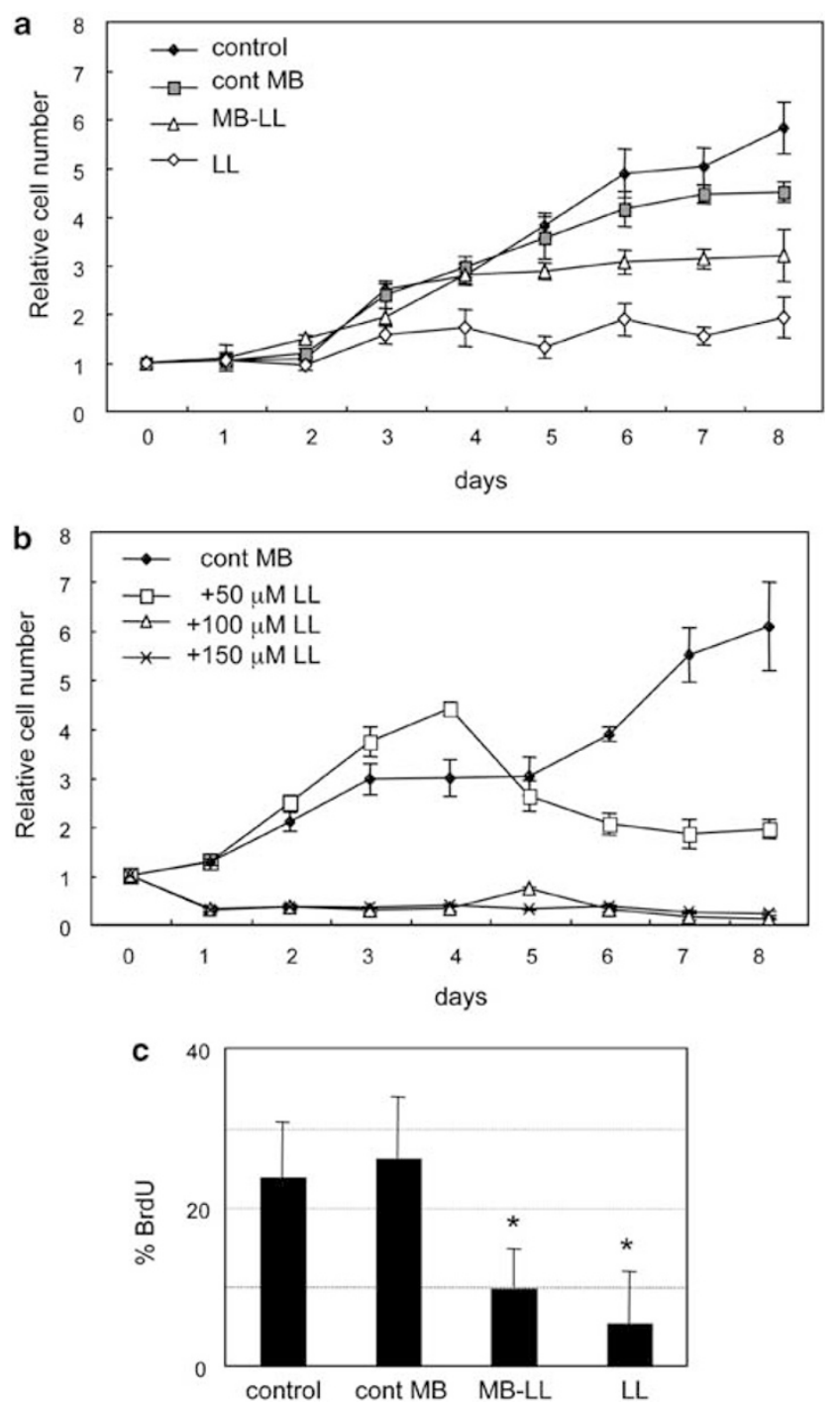

Figure 4 Lysolecithin (LL; $100 \mu \mathrm{M})$ and model bile (MB) containing LL $(100 \mu \mathrm{M} ; \mathrm{MB}-\mathrm{LL})$ induce growth arrest in human gallbladder epithelial cells (HGECs) compared to the control treated with control MB or the same concentration of ethanol. (a) Proliferation curve based on results of WST-1 assays. Data are shown as mean \pm s.d. (b) Proliferation curve of HGECs treated with control MB containing $\operatorname{LL}(0,50,100$, and $150 \mu \mathrm{M})$ based on results of WST-1 assays. Data are shown as mean \pm s.d. (c) Cell proliferation assessed by the BrdU assay on day 4 (mean and s.d.). ${ }^{\star} P<0.01$ vs control and cont MB.

positive cells was significantly increased by LL treatment (100 $\mu \mathrm{M}, 4$ days) and to a lesser degree, by MB-LL treatment (Figure 5a and b). Immunofluorescence showed that $\gamma \mathrm{H} 2 \mathrm{AX}$ foci were present in the nuclei of HGECs treated with LL ( $100 \mu \mathrm{M}$, 4days; Figure $5 \mathrm{c})$. Western blot assays showed an increase of $\gamma \mathrm{H} 2 \mathrm{AX}$ and $\mathrm{p} 16^{\mathrm{INK} 4 \mathrm{~A}}$ in parallel in the cells treated with LL (Figure 5d).

Overexpression of EZH2 in Senescent Cells Causes Reduced Expression of p16 $6^{I N K 4 A}$. To clarify whether senescent cells can escape growth arrest or not, cultured HGECs were first 
a

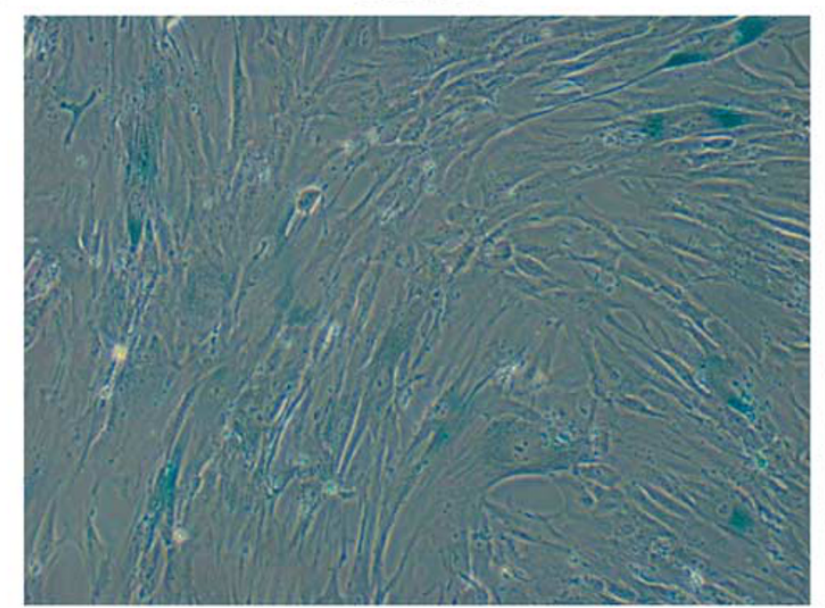

b day

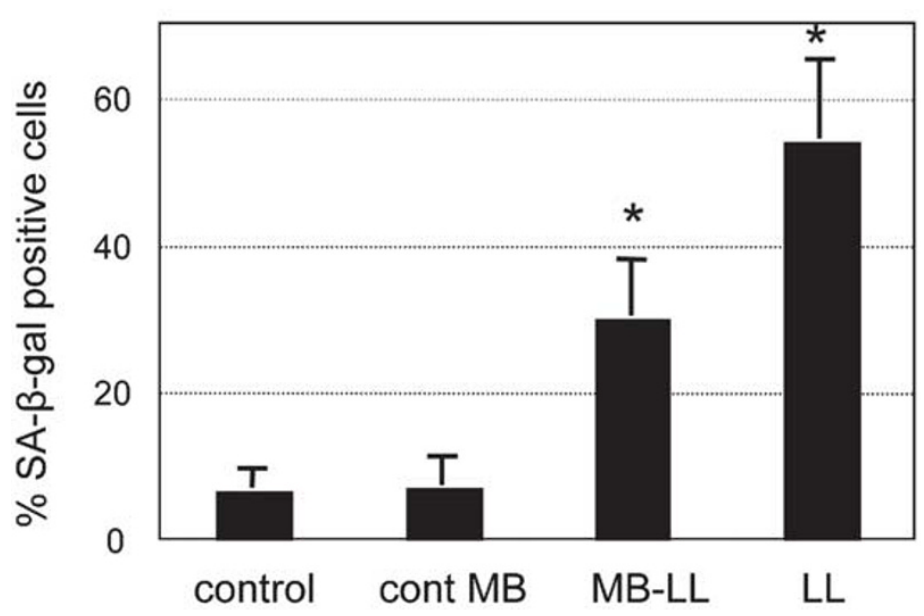

d

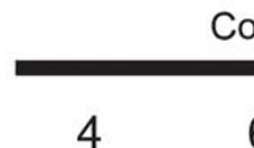

Control

6 control

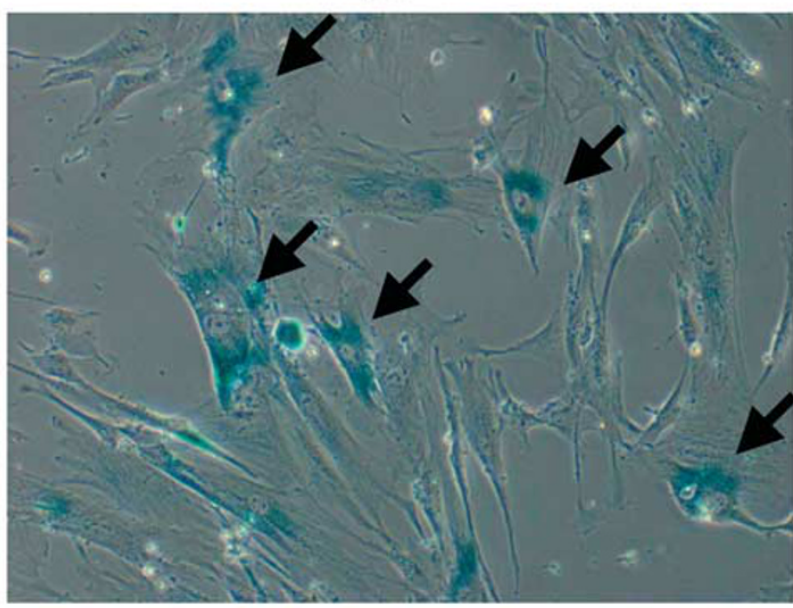

c

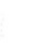

\section{control}

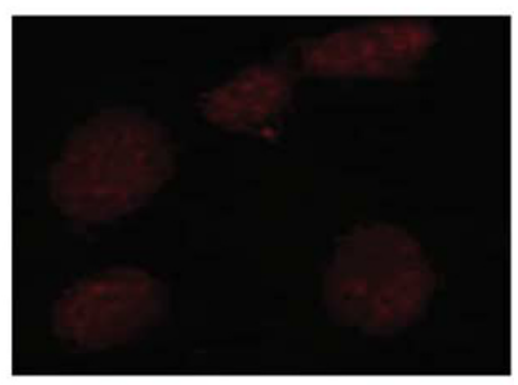

LL

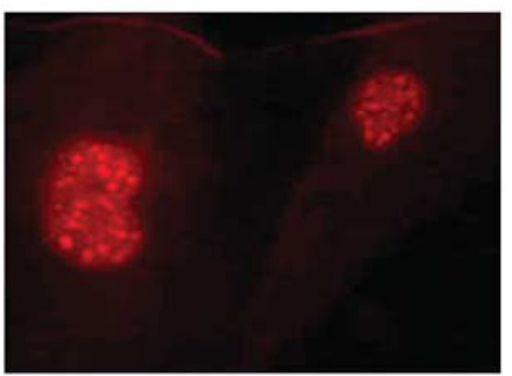

LL

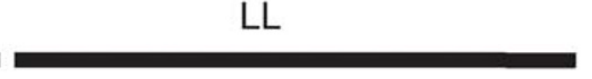

8

\section{p16 INK4A}

$\gamma \mathrm{H} 2 \mathrm{AX}$

\section{$\beta$-actin}

Figure 5 Lysolecithin (LL) induces SA- $\beta$-Gal activity, and $\mathrm{p} 16^{\mathrm{INK} 4 \mathrm{~A}}$ and $\gamma \mathrm{H} 2 \mathrm{AX}$ expression. (a and b) Cellular senescence was assessed based on SA- $\beta$-Gal activity on day 4. Percentage of SA- $\beta$-Gal-positive cells was significantly higher in the LL (100 $\mu \mathrm{M})$-treated group and the model bile containing LL (100 $\mu \mathrm{M}$; MB-LL)- treated group (mean and s.d.) ${ }^{*} P<0.01$ vs control and cont MB. (c) Immunofluorescence for $\gamma \mathrm{H} 2 \mathrm{AX}$. $\gamma \mathrm{H} 2 \mathrm{AX}$ expression labeled by red fluorescent was found in nuclei of the cells in the form of multiple foci on day 4. (d) Western blot for p16 $6^{\mathrm{INK} 4 \mathrm{~A}}$ and $\gamma \mathrm{H} 2 \mathrm{AX}$ expression in cell lysate of human gallbladder epithelial cells (HGECs) treated with LL or ethanol (control). 


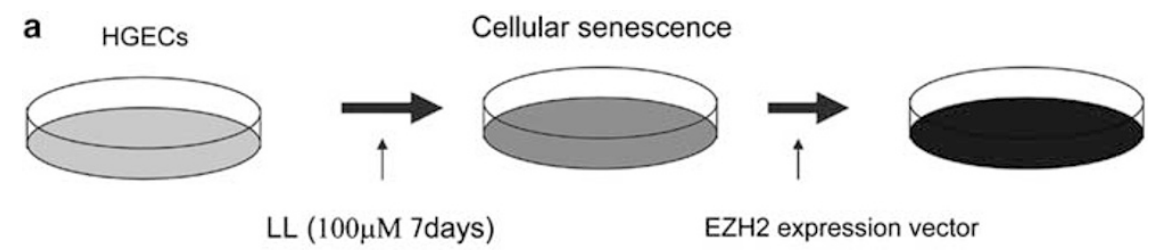

b

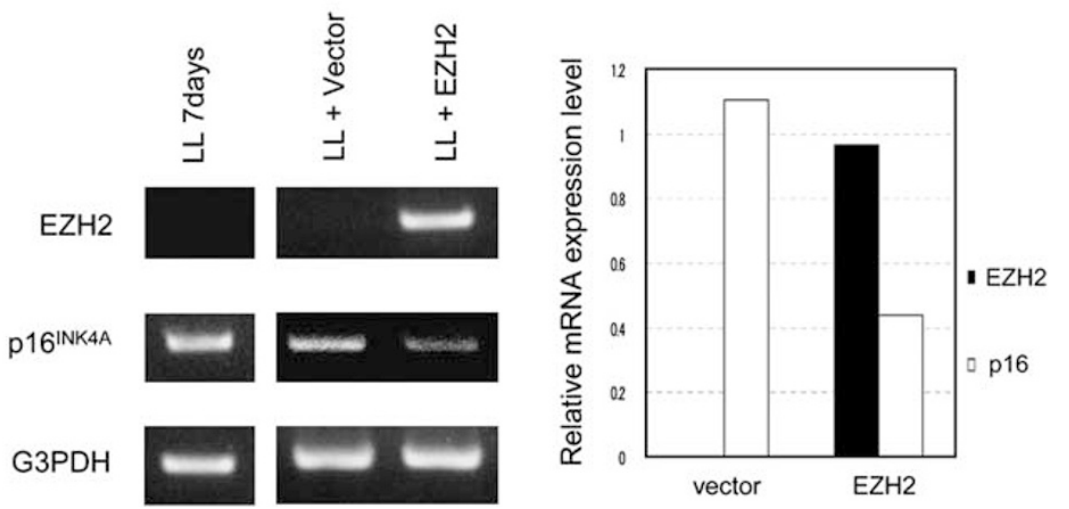

Figure 6 Transfection of plasmid and overexpression of EZH2 in senescent human gallbladder epithelial cells (HGECs). (a) Schema of experiments. (b) Image of RT-PCR of EZH2 and p16 $6^{\text {INK4A }} 1$ day after transfection of plasmid. Graph shows a semiquantitative analysis of the gel image compared with G3PDH expression.

treated with LL $(100 \mu \mathrm{M})$ for 7 days so as to enter a senescent state, and then, transfected with the EZH2 expression plasmid (Figure 6a). RT-PCR showed that the expression of p $16^{\mathrm{INK} 4 \mathrm{~A}}$ was considerably inhibited in contrary to that of EZH2 in the cells treated with the EZH2 plasmid in comparison to those treated with the control vector (Figure 6b).

\section{Studies using cultured human gallbladder carcinoma cells} Knockdown of EZH2 Results in Decrease in Proliferation. As the expression level of EZH2 was low in PHP in PBM and high in CarGB, we hypothesized that EZH2 induces escape/ bypass of cellular senescence. Therefore, we examined whether the knockdown of EZH2 by siRNA affects the proliferation and senescence of TGBC2TKB cells.

EZH2 level was high in TGBC2TKB cells in comparison to that in HGECs (Figure 7a). RT-PCR showed the effective knockdown of EZH2 by siRNA treatment in comparison to the control siRNA treatment 1 day after treatment (Figure $7 b$ ). In vitro BrdU assay was performed 2 days after the siRNA treatment in TGBC2TKB cells. Proliferative activity was significantly reduced after treatment with EZH2 siRNA in comparison to that in cells treated with control siRNA (Figure 7c), suggesting that the knockdown of EZH2 by siRNA treatment decreased the proliferative activity of these TGBC2TKB cells.

Knockdown of EZH2 Induces SA- $\beta$-Gal and $p 16^{I N K 4 A}$ Expression in TGBC2TKB Cells. To examine whether senescence may be responsible for the decreased cell proliferation caused by EZH2 siRNA, we examined the expression of senescence markers in TGBC2TKB cells treated with EZH2 siRNA. SA- $\beta$ -
Gal assay performed 4 days after the siRNA treatment showed that the number of SA- $\beta$-Gal -positive cells was significantly increased in comparison to the control (Figure $7 \mathrm{~d}$ and e). Furthermore, RT-PCR showed the increased expression of p16 ${ }^{\mathrm{INK} 4 \mathrm{~A}}$ (Figure 7b) and immunofluorescence also revealed the expression of $\mathrm{p} 16^{\text {INK4A }}$ (Figure $7 \mathrm{f}$ ) in cultured TGBC2TKB cells of the EZH2 knockdown group.

\section{DISCUSSION}

The results of this study can be summarized as follows: (1) PHP of the gallbladder mucosa was found in all cases of PBM but not in cholecystolithiasis, whereas BilIN-1/2 was found in cholecystolithiasis but not PBM. (2) BilIN-1/2 showed frequent expression of EZH2 and increased cellular proliferative activities as seen in CarGB including BillN-3, whereas PHP showed an increased expression of $\mathrm{p}^{\mathrm{INK} 4 \mathrm{~A}}$ (a senescence marker) and formation of $\gamma \mathrm{H} 2 \mathrm{AX}$ foci (a DNA damage marker), and low cell proliferative activities. (3) LL induced the expression of senescence markers, and also the formation of $\gamma \mathrm{H} 2 \mathrm{AX}$ foci, and induced growth arrest in cultured HGECs. Enforced overexpression of EZH2 in senescent HGECs caused decreased expression of $\mathrm{p} 16^{\mathrm{INK} 4 \mathrm{~A}}$. (4) Knockdown of EZH2 in cultured TGBC2TKB cells resulted in a decrease in cell proliferation and induced the expression of senescent markers.

Aberrant expression of EZH2 is regarded as a potential marker of aggressive cancers and also indicates an increased risk of malignant transformation. ${ }^{14}$ In fact, our recent study showed that EZH2 was overexpressed in BilIN-1/2, BilIN-3, and invasive carcinoma of stone-containing intrahepatic large bile ducts. ${ }^{12}$ This study also showed that EZH2 was 
a

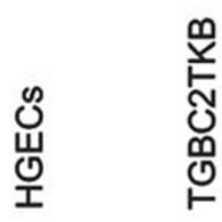

EZH2

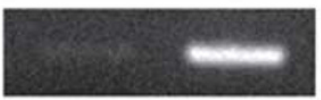

G3PDH

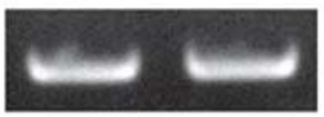

c

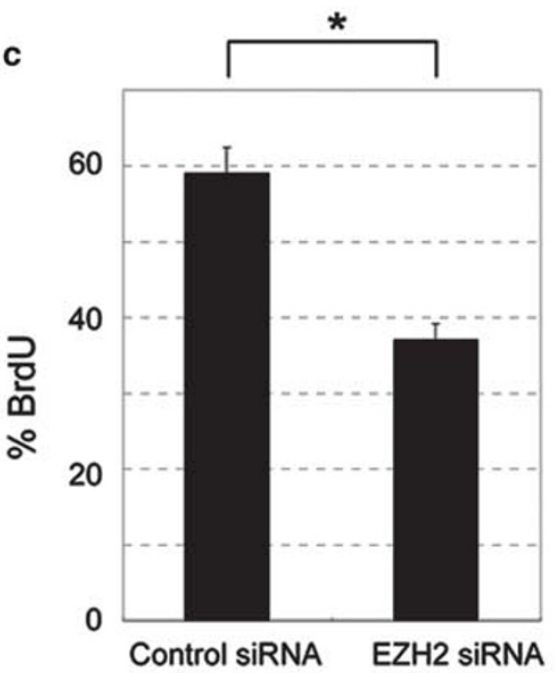

e

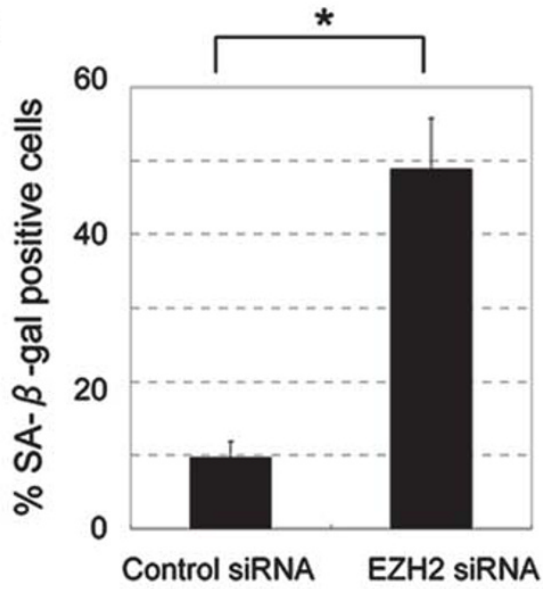

b
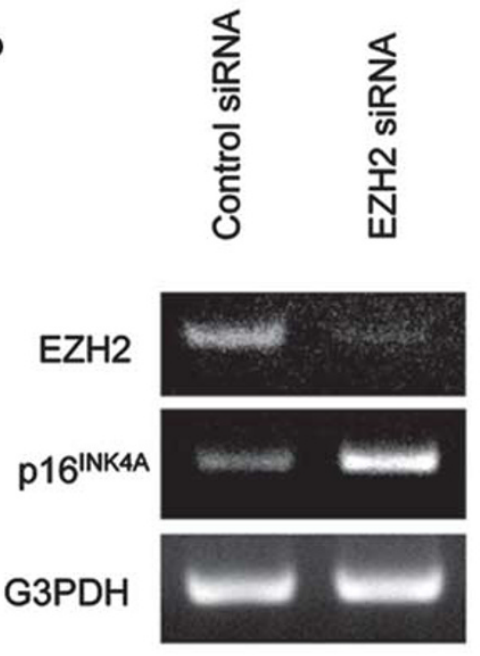

d

control siRNA

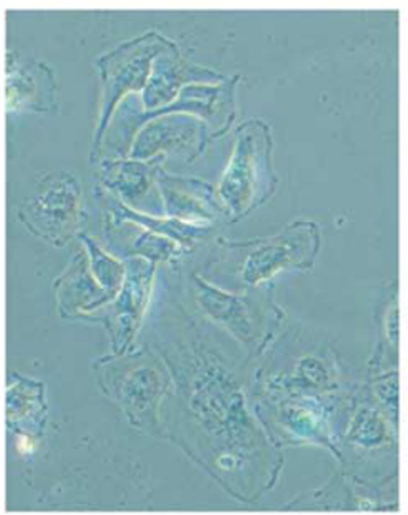

f
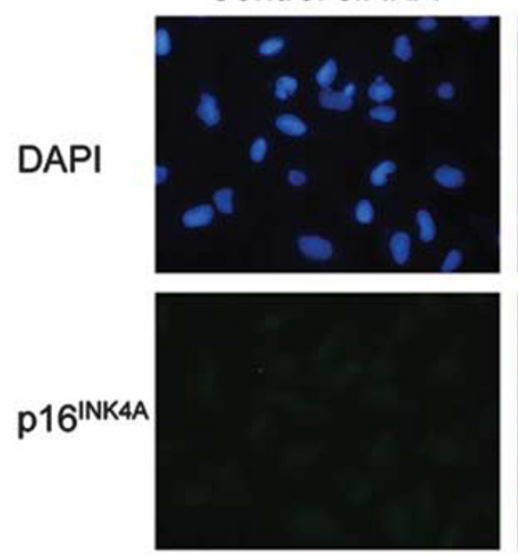

EZH2 SiRNA

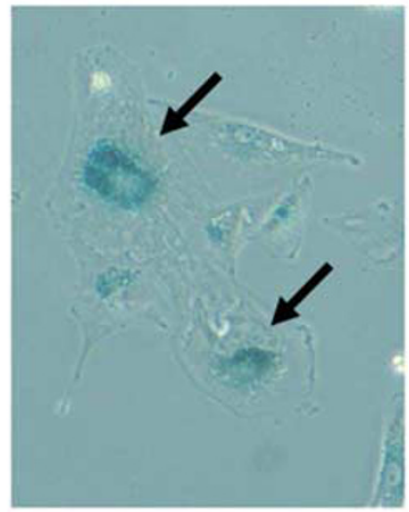

EZH2 siRNA
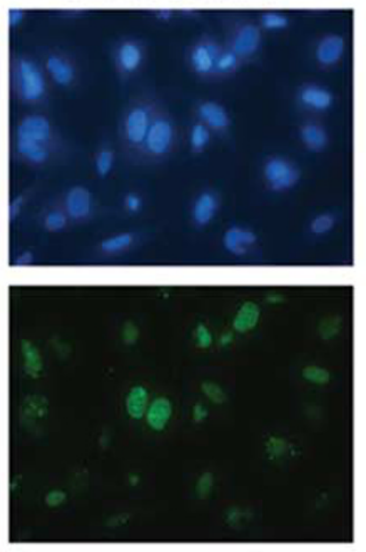

Figure 7 Knockdown of EZH2 in a gallbladder carcinoma cell line (TGBC2TKB) by siRNA treatment. (a) RT-PCR showed the expression of EZH2 in TGBC2TKB cells compared to human gallbladder epithelial cells (HGECs). (b) Image of RT-PCR of EZH2 and p16 $6^{\text {INK4A }}$ on day 1 after siRNA treatment. (c) Cell proliferation assessed by BrdU assay on day 4 (mean \pm s.d.). ${ }^{*} P<0.01$. (d and e) Cellular senescence was assessed based on SA- $\beta$-Gal activity on day 4 (mean \pm s.d.). ${ }^{*} P<0.01$ (f) Immunofluorescence showed expression of $p 16^{\mathrm{INK} 4 \mathrm{~A}}$ in nuclei labeled by green fluorescent on day 4 . 
frequently expressed in BillN-1/2 and CarGB including BiIIN-3 in cholecystolithiasis. Taken together, similar carcinogenetic processes may be operative in the large bile duct in hepatolithiasis and also in the gallbladder in cholecystolithiasis.

Biliary tract carcinoma is frequently accompanied by $\mathrm{PBM}^{4-6}$ and in fact, CarGB was found in 4 of the 15 cases of PBM examined here. PHP was found in the gallbladder in all PBM cases and $\mathrm{p} 16^{\mathrm{INK} 4 \mathrm{~A}}$ was frequently expressed in PHP. $\mathrm{p} 16^{\mathrm{INK} 4 \mathrm{~A}}$, a major tumor suppressor, is inactivated in a variety of human cancers. ${ }^{12}$ Interestingly, it was found in this study that the expression level of EZH2 was inversely correlated with that of $\mathrm{p} 16^{\mathrm{INK} 4 \mathrm{~A}}$ in PHP and BilIN-1/2 in cholecystolithiasis; the $\mathrm{p} 16^{\mathrm{INK} 4 \mathrm{~A}}$-predominant expression was exclusively found in PHP, and in contrast, EZH2 was predominant in BiIN-1/2. These differences between BilIN-1/2 and PHP suggest that the gallbladder carcinogenesis in PBM is different from that in cholecystolithiasis. However, EZH2 was similarly expressed in BilIN-3 and invasive carcinoma in the gallbladders with PBM as seen in those with cholecystolithiasis, suggesting that EZH2 also participates in the malignant transformation in PHP in the gallbladder of PBM patients, whereas BilIN-1/2 are not related to this carcinogenesis.

This study showed that the expression of $\mathrm{p} 16^{\mathrm{INK} 4 \mathrm{~A}}$ was highly frequent in PHP of the gallbladder of PBM. In addition, cell proliferative activities of PHP were quite low. Reportedly, p16 ${ }^{\mathrm{INK} 4 \mathrm{~A}}$ protein is frequently expressed in senescent cells in vivo, ${ }^{25}$ and this protein is thought to be a causative factor of senescence. ${ }^{25} \mathrm{p} 16^{\mathrm{INK} 4 \mathrm{~A}}$ is also known as an effecter of in vitro oncogene-induced senescence. ${ }^{26}$ Taken together, it seems possible that PHP lesion reflects cellular senescence.

Early tumorigenesis is associated with the DNA-damage checkpoint response (DDR) ${ }^{27}$ which can arrest the cell cycle on detection of DNA damage. Activation of DDR contributes to oncogene-induced senescence, and senescent cells have clearly detectable foci of senescence-associated DNA-damage. These foci contain activated DDR mediators such as 53BP1 and MDC1, together with $\gamma \mathrm{H}_{2} \mathrm{AX}^{21}$ This study showed that $\gamma \mathrm{H} 2 \mathrm{AX}$ was quite frequently expressed in PHP in the gallbladder in PBM, supporting that PHP lesions of the gallbladder of PBM patients represent a senescent state.

In human naevi, which is regarded as an oncogene-induced cellular senescent lesion, $\mathrm{p} 16^{\mathrm{INK} 4 \mathrm{~A}}$-positive cells and staining intensity were heterogeneous with a striking mosaic pattern. ${ }^{17}$ p $16^{\text {INK4A }}$ immunoreactivity was also heterogeneous in cultured senescent human melanocytes induced by BRAF in spite that over $95 \%$ of these cells were arrested. ${ }^{17}$ Similar to these observations in the naevi and cultured senescent cells, p16 immunopositivity was heterogeneous with a mosaic pattern in most PHP of the gallbladder in PBM. However, $\gamma \mathrm{H} 2 \mathrm{AX}$-positive cells and intensity were homogeneous in the PHP, suggesting that $\gamma \mathrm{H} 2 \mathrm{AX}$ is a more sensitive marker of senescence, especially in paraffin-embedded specimens.

In patients with PBM, the LL level is reported to be elevated in bile of gallbladder. ${ }^{4,6}$ However, the role of LL in the biliary tract pathology in PBM remains speculative. Under the hypothesis that LL is involved in the formation of PHP with cellular senescence features in the gallbladder, we treated cultured HGECs with LL. It was found that the proliferative activity of HGECs was markedly inhibited by LL treatment and the growth curve reached the plateau by day 4 . In addition, LL induced SA- $\beta$-Gal activity and $\mathrm{p} 16^{\mathrm{INK} 4 \mathrm{~A}}$ protein expression in cultured HGECs, supporting that an elevated LL level in gallbladder bile might have been responsible for the development and maintenance of the senescence characterizing PHP in PBM. It is of interest that HGECs treated with control model bile with LL $(50 \mu \mathrm{M})$ showed rather high growth rate in early phase and then, growth arrest. This phenomenon may be related to the formation of PHP followed by cellular senescence.

After the treatment with LL, $\gamma \mathrm{H} 2 \mathrm{AX}$ foci were also detectable in HGECs. Interestingly, western blotting showed that $\gamma \mathrm{H} 2 \mathrm{AX}$ expression was found before the elevation of p $16^{\mathrm{INK} 4 \mathrm{~A}}$ levels in cultured HGECs treated with LL. The serial activation of $\gamma \mathrm{H} 2 \mathrm{AX}$ and $\mathrm{p} 16^{\mathrm{INK} 4 \mathrm{~A}}$ in this sequence is compatible with the notion that DNA damage and the DDR process induce cellular senescence, and LL may be involved in this induction in the PHP of the gallbladder.

This study showed that PHP was consistently found in the gallbladder of PBM patients and showed features of senescence and low cell proliferative activities. These characteristics were induced in cultured HGECs by treatment with LL, the concentration of which is reportedly high in the gallbladder bile of PBM, ${ }^{4}$ suggesting that an elevated LL level in bile might have induced cellular senescence and PHP in the gallbladder and this senescent-related lesion may protect against malignant transformation in PBM for decades. Human naevi is known to be a senescent-related lesion that also protects against malignant transformation, ${ }^{17}$ and PHP of the gallbladder could be another good model of senescence-related lesions against malignant transformation.

In adult PBM patients, carcinomas develop not infrequently in the biliary tract including the gallbladder. ${ }^{3-7}$ Interestingly, the prevalence of biliary tract carcinoma in PBM patients increases with age with a peak at 50 years, ${ }^{3-7}$ whereas PHP is found from childhood to adulthood, raising a possibility that gallbladder mucosa showing PHP can act as a safeguard against malignant transformation for decades. This study showed that whereas EZH2 was not expressed in the PHP of the gallbladder in PBM, BilIN-3 and invasive carcinoma in the four cases of PBM with PHP expressed EZH2, suggesting that an aberrant expression of EZH2 is involved in the malignant transformation from PHP in the gallbladder in adult PBM and induces a bypass of or escape from PHP.

To evaluate whether senescent gallbladder epithelial cells can escape growth arrest or not, an EZH2 expression plasmid 
was transfected into senescent cultured HGECs first treated with LL. As expected, p16 $6^{\mathrm{INK} 4 \mathrm{~A}}$ was inhibited in the cells transfected with the EZH2 plasmid. However, cell proliferation was not significantly affected (data not shown). It is reported that ectopic overexpression of EZH2 did not enhance growth of cells but induced anchorage-independent growth and cell invasion in breast cells. ${ }^{28}$ The cell proliferation was not enhanced in our study, however, the reduction of $\mathrm{p} 16^{\mathrm{INK} 4 \mathrm{~A}}$ indicates the possibility that senescent cells can return to a proliferative state and EZH2 overexpression may play a role in this transformation and may give these cells invasive behavior.

Then, we tried to examine whether characteristic features of senescence can be induced in TGBC2TKB cells by knockdown of EZH2 using EZH2 siRNA. It was found that the number of SA- $\beta$-Gal -positive cells was significantly increased by the treatment with EZH2 siRNA. Furthermore, RT-PCR showed the increased expression of $\mathrm{p} 16^{\mathrm{INK} 4 \mathrm{~A}}$ and immunofluorescence also revealed the expression of $\mathrm{p} 16^{\mathrm{INK} 4 \mathrm{~A}}$ in the cultured TGBC2TKB cells of the EZH2 knockdown group, suggesting that the upregulation of EZH2 expression is strongly involved in the cell proliferative activities of TGBC2TKB cells.

In conclusion, PHP of the gallbladder in PBM may represent a senescent-related lesion, which could be induced by LL in bile. This lesion may be involved in safeguarding against malignant transformation of gallbladder mucosa in PBM for decades. On the other hand, BilIN-1/2 found in the gallbladder of cholecystolithiasis seems to be a premalignant lesion followed by malignant transformation in which EZH2 may be involved. EZH2 may also play an important role in escaping from senescence in the gallbladder with PHP.

\section{DISCLOSURE/CONFLICT OF INTEREST}

The authors declare no conflict of interest.

1. Albores-saavedra J, Scoazec JC, Wittekind C, et al. World Health Organization Classification of Tumors, Pathology and Genetics, Tumor of the Digestive System; Carcinoma of the Gallbladder and Extrahepatic Bile Ducts. International Agency for Research on Cancer: Lyon, 2000.

2. Albores-saavedra J, Henson DE, Klimstra DS. Tumors of the gallbladder, extrahepatic bile ducts, and ampulla of vater. In: Atlas of Tumor Pathology. Armed Forces Institute of Pathology: Washington, DC, Third Series, Fascicle 27 1998, pp 1-360.

3. Miyazaki M, Takada T, Miyakawa S, et al. Risk factors for biliary tract and ampullary carcinomas and prophylactic surgery for these factors. J Hepatobiliary Pancreat Surg 2008;15:15-24.

4. Sugiyama $\mathrm{Y}$, Kobori $\mathrm{H}$, Hakamada $\mathrm{K}$, et al. Altered bile composition in the gallbladder and common bile duct of patients with anomalous pancreaticobiliary ductal junction. World J Surg 2000;24:17-21.

5. Yamato $\mathrm{T}$, Kurumaya $\mathrm{H}$, Ohama $\mathrm{K}$, et al. Frequent expression of mucin core protein MUC1 in non-neoplastic gallbladder mucosa from patients with pancreaticobiliary maljunction. Liver 1999;19:281-287.

6. Seki $M$, Yanagisawa $A$, Ninomiya $E$, et al. Clinicopathology of pancreaticobiliary maljunction: relationship between alterations in background biliary epithelium and neoplastic development. J Hepatobiliary Pancreat Surg 2005;12:254-262.
7. Shimada K, Yanagisawa J, Nakayama F. Increased lysophosphatidylcholine and pancreatic-enzyme content in bile of patients with anomalous pancreaticobiliary ductal junction. Hepatology 1991;13:438-444.

8. Adham A, Valette PJ, Partensky C. Pancreaticobiliary maljunction without choledochal dilatation associated with gallbladder cancer: report of 2 European cases. Surgery 2005;138:961-961.

9. Beltran MA, Vracko J, Cumsille MA, et al. Occult pancreaticobiliary reflux in gallbladder cancer and benign gallbladder diseases. J Surg Oncol 2007;96:26-31.

10. Sai JK, Suyama M, Nobukawa B, et al. Precancerous mucosal changes in the gallbladder of patients with occult pancreatobiliary reflux. Gastrointest Endosc 2005;61:264-268.

11. Zen $Y$, Aishima S, Ajioka Y, et al. Proposal of histological criteria for intraepithelial atypical/proliferative biliary epithelial lesions of the bile duct in hepatolithiasis with respect to cholangiocarcinoma: preliminary report based on interobserver agreement. Pathol Int 2005;55:180-188.

12. Sasaki M, Yamaguchi J, Itatsu K, et al. Over-expression of polycomb group protein EZH2 relates to decreased expression of p16(INK4a) in cholangiocarcinogenesis in hepatolithiasis. J Pathol 2008;215: $175-183$.

13. Varambally $S$, Dhanasekaran SM, Zhou M, et al. The polycomb group protein EZH2 is involved in progression of prostate cancer. Nature 2002;419:624-629.

14. Ding L, Erdmann C, Chinnaiyan AM, et al. Identification of EZH2 as a molecular marker for a precancerous state in morphologically normal breast tissues. Cancer Res 2006;66:4095-4099.

15. Braig M, Schmitt CA. Oncogene-induced senescence: putting the brakes on tumor development. Cancer Res 2006;66:2881-2884.

16. Collado M, Gil J, Efeyan A, et al. Tumour biology-senescence in premalignant tumours. Nature 2005;436:642-642.

17. Michaloglou C, Vredeveld LCW, Soengas MS, et al. BRAF(E600)associated senescence-like cell cycle arrest of human naevi. Nature 2005;436:720-724.

18. Noda Y, Fujita N, Kobayashi G, et al. Histological study of gallbladder and bile duct epithelia in patients with anomalous arrangement of the pancreaticobiliary ductal system: comparison between those with and without a dilated common bile duct. J Gastroenterol 2007;42 211-218.

19. Collado $M$, Serrano $M$. The power and the promise of oncogeneinduced senescence markers. Nat Rev Cancer 2006;6:472-476.

20. Bartkova J, Rezaei N, Liontos $M$, et al. Oncogene-induced senescence is part of the tumorigenesis barrier imposed by DNA damage checkpoints. Nature 2006;444:633-637.

21. Tanaka T, Halicka HD, Huang $X$, et al. Constitutive histone H2AX phosphorylation and ATM activation, the reporters of DNA damage by endogenous oxidants. Cell Cycle 2006;5:1940-1945.

22. Harada K, Ohba K, Ozaki S, et al. Peptide antibiotic human betadefensin- 1 and -2 contribute to antimicrobial defense of the intrahepatic biliary tree. Hepatology 2004;40:925-932.

23. Tazuma S, Holzbach T. Transport of conjugated bilirubin and other organic anions in bile: relation to biliary lipid structures. Proc Natl Acad Sci USA 1987;84:2052-2056.

24. Melcher M, Schmid M, Aagaard L, et al. Structure-function analysis of SUV $39 \mathrm{H} 1$ reveals a dominant role in heterochromatin organization, chromosome segregation, and mitotic progression. Mol Cell Biol 2000;20:3728-3741.

25. Campisi J. Senescent cells, tumor suppression, and organismal aging: good citizens, bad neighbors. Cell 2005;120:513-522.

26. Alcorta DA, Xiong $Y$, Phelps $D$, et al. Involvement of the cyclindependent kinase inhibitor p16 (INK4a) in replicative senescence of normal human fibroblasts. Proc Natl Acad Sci USA 1996;93: 13742-13747.

27. Halazonetis TD, Gorgoulis VG, Bartek J. An oncogene-induced DNA damage model for cancer development. Science 2008;319: 1352-1355.

28. Kleer CG, Cao Q, Varambally S, et al. EZH2 is a marker of aggressive breast cancer and promotes neoplastic transformation of breast epithelial cells. Proc Natl Acad Sci USA 2003;100:11606-11611. 